\title{
Mutants of the Arginine-proline Pathway in Aspergillus nidulans
}

\author{
By MALGORZATA PIOTROWSKA, M. SAWICKI \\ AND P. WEGLENSKI \\ Department of Genetics, Warsaw University, Al. Ujazdowskie 4, Warsaw, Poland
}

(Accepted for publication 14 October I968)

\section{SUMMARY}

Proline suppressor mutant su- 19 was analysed for arginase and ornithine $\delta$-transaminase (OTA) activity. Both enzymes are constitutively produced by this mutant. Five other suppressor loci not linked with $s u-19$ or to each other are involved in regulation of the two enzymes.

A mutant showing no OTA activity was isolated. Properties of this mutant and its effect in various strains of the pro su type were studied.

\section{INTRODUCTION}

Mutants of one (su-I9) out of three proline suppressor loci studied previously in Aspergillus nidulans showed the constitutive synthesis of ornithine $\delta$-transaminase (OTA), the enzyme involved in the conversion of ornithine to glutamic $\gamma$-semialdehyde (GSA) (Weglenski, I966, 1967). It was suggested that due to high level of the OTA in $s u-I 9$ strain, ornithine is diverted from the arginine pathway and utilised for GSA and proline synthesis. Thus, mutations in the $s u-I g$ locus were considered responsible for opening the alternative route of the proline synthesis which by-passes the metabolic block (between glutamate and GSA) in the major proline pathway. Assays for arginase showed that the activity of this enzyme is also higher than in the wild strain. However, the arginase results were not reliable as the assay procedure applied does not work well in $A$. nidulans (cf. Weglenski, 1967); moreover, all assays were carried out with strains of the pro su type and not of the $\mathrm{pro}^{+} s u$ type. As previously shown (Weglenski, 1967), the presence of the pro mutation strongly influences the activity of the enzymes metabolizing arginine. The relations between the pathways of arginine and proline synthesis are shown in Fig. I.

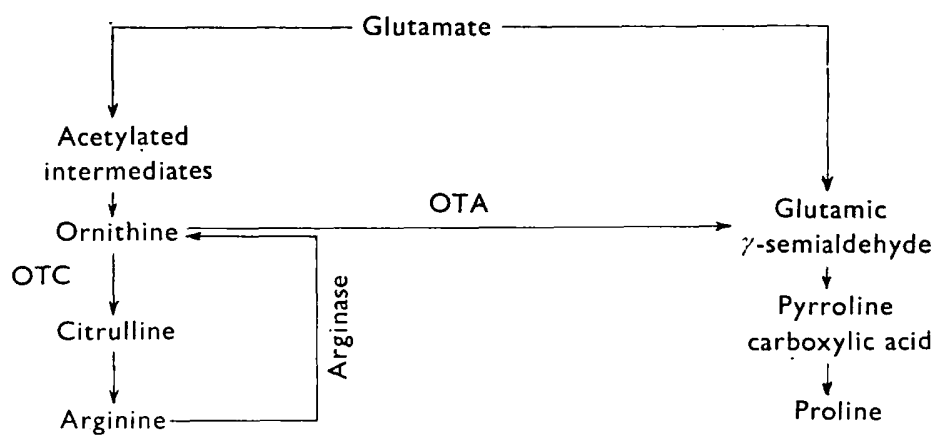

Fig. 1. Aspergillus nidulans: the pathway of proline and arginine synthesis. OTC, ornithine transcarbamylase; OTA, ornithine $\delta$-transaminase. 
The aim of the experiments presented in this paper was: (I) to obtain the $\mathrm{pro}^{+} s u-I 9$ strain and to test if the su-19 mutation affects only OTA or both OTA and arginase synthesis, (2) to test if other loci are involved in regulation of arginase and/or OTA synthesis, (3) to select OTA deficient mutants and to construct a strain blocked both in the major and in the alternative pathway of proline synthesis, which would make it possible to test decisively whether the opening of the alternative pathway is responsible for the suppression phenomenon in the case of $s u-I 9$ and other suppressor loci.

\section{METHODS}

Media and standard techniques used in this work were as in Pontecorvo et al. (1953).

Material. All proline suppressor mutants except $s u-I$ were obtained as spontaneous mutants from the pro-6 pab-9 bio-I or the pro-6 ade-9 y phe-2 strains (Weglenski, 1966). Strain pro-I su-I was obtained from the Department of Genetics, Glasgow University.

Isolation of mutants. Conidia of the pro-6 su-I9 pab-9 bio-I strain were treated for I hr with $N$-methyl- $N^{\prime}$-nitro- $N$-nitrosoguanidine $(500 \mu \mathrm{g} . / \mathrm{ml}$.$) . After removing$ mutagen conidia were resuspended in water and plated on the medium containing all required supplements. Colonies obtained were tested by needle inoculations for growth on a prolineless medium.

Isolation of the pro $^{+}$su-I9 strain. Locus su-I9 maps on chromosome I between pro-I (an allele of pro-6) and ade-9 showing with these two loci about 6 and $4 \%$ recombination respectively. To obtain the $\mathrm{pro}^{+} s u-I 9$ strain the following cross was made:

$$
\frac{\text { pro-6 su-19 }+ \text { pab-9 }+ \text { bio-I }}{++ \text { ade-9 }+y+} \text {. }
$$

From the progeny of this cross colonies of the pab bio phenotype were selected and tested in heterokaryons against the pro-6 ade-9 y phe-2 strain. By this method pro-6 can be distinguished from the pro $^{+}$colonies since those belonging to the former class will not form heterokaryons which can grow on the prolineless medium. To the latter class belong colonies of the $\mathrm{pro}^{+} s u^{+}$pab-9 bio-I and $\mathrm{pro}^{+} s u-19 \mathrm{pab}-9 \mathrm{bio}-\mathrm{I}$ genotypes, which can be distinguished after crossing them with the pro-6 su-rg strain. If a colony used in the cross was pro $^{+} s u-19$, no proline requiring progeny will be obtained.

Methods of culture and harvesting mycelium and of enzyme extraction and assay for OTA were as previously described (Weglenski, 1967).

Assay of arginase. $0.2 \mathrm{ml}$. of enzyme extract (equiv. $0.3 \mathrm{mg}$. protein) in $0.1 \mathrm{M}$ potassium phosphate buffer $\left(\mathrm{pH} 7 \cdot 0\right.$ ) was preincubated at $37^{\circ}$ for I hr with $0.1 \mu$ mole of $\mathrm{MnCl}_{2}$. After preincubation $50 \mu$ mole of arginine- $\mathrm{HCl}, \mathrm{pH} 10 \cdot 0$, were added and the reaction mixture was incubated for $20 \mathrm{~min}$. at $37^{\circ}$; total volume of reaction mixture $\mathrm{I} \cdot 0 \mathrm{ml}$. The reaction was stopped by adding $0.2 \mathrm{ml} .0 .2 \mathrm{M}-\mathrm{HCl}$. Urea formed in the reaction was split to ammonium by adding an excess of urease. Ammonium was estimated by the Conway microdiffusion method (Conway, I962).

Determination of protein. Protein estimations were made according to the Lowry, Rosebrough, Farr \& Randall (I95I) method, with crystalline bovine serum albumin as a standard.

Abbreviations used: pro $=$ proline $;$ ade $=$ adenine $;$ pab $=$ p-aminobenzoic acid; phe $=$ phenylalanine $;$ bio $=$ biotin $; y=$ yellow conidia $; s u=$ suppressor. 


\section{RESULTS}

su-I9 and other mutants constitutive for arginase and OTA synthesis

Activities of arginase and OTA were compared in pro-6 su-19, pro $^{+} s u-19$ and wild strains. The high level of synthesis of both enzymes results from the suppressor mutation and is not influenced by the presence or absence of the pro-6 mutation (Table I). Several other suppressor mutants were tested for arginase and OTA activities. Five suppressor mutants showed constitutive levels of both enzymes (Table I). All these mutants are recessive and they complement with su-I9 and with each other. Crosses were made of all possible pairs of these suppressors. No linkage between suppressor loci was observed. One suppressor mutant which we studied, $s u-I$, was isolated and mapped by Forbes (I956) in linkage group III. Two other mutants, $s u-I I$ and $s u-22$ were assigned to linkage groups $\mathrm{V}$ and III respectively by means of mitotic haploidisation (Sawicka, personal communication).

Table I. Aspergillus nidulans: specific activities of arginase and ornithine $\delta$-transaminase (OTA) in wild, ota-I and various suppressor strains

\begin{tabular}{|c|c|c|}
\hline Strain & $\begin{array}{c}\text { Arginase activity } \\
\left(\mu \mathrm{g} . \mathrm{N}-\mathrm{NH}_{3} / \mathrm{mg}\right. \\
\text { protein } / \mathrm{min} .)\end{array}$ & $\begin{array}{l}\text { OTA activity } \\
(\mathrm{m} \mu \mathrm{mole} \\
\text { ornithine } / \mathrm{mg} . \\
\text { protein } / \mathrm{min} .)\end{array}$ \\
\hline Wild & $4 \cdot 0$ & 12 \\
\hline Wild, induced by arginine & $39 \cdot 1$ & About 200 \\
\hline pro-6 su-I9 & $28 \cdot 5$ & 144 \\
\hline pro $^{+}$su-I9 & $27 \cdot 8$ & 145 \\
\hline pro-6 $s u-I I$ & $26 \cdot 7$ & 163 \\
\hline pro-6 $s u-22$ & $25 \cdot 8$ & 134 \\
\hline pro-6 $s u-I$ & $23 \cdot 8$ & 128 \\
\hline pro-6 su-3o & $24 \cdot 2$ & 150 \\
\hline pro-6 su-35 & $26 \cdot 5$ & 171 \\
\hline pro-6 su-I9 ota-I & $30 \cdot 2$ & About I \\
\hline prot $^{+} \mathrm{su}^{+}$ota-I & $3 \cdot 8$ & About I \\
\hline
\end{tabular}

Table 2. Aspergillus nidulans: crosses involving the ota-I mutant

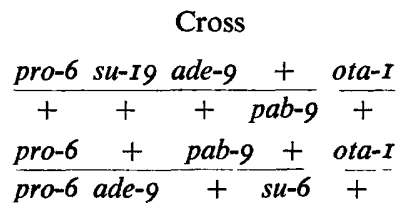

Isolation and characterisation of the ota-I mutant

$\begin{array}{ccc}\begin{array}{c}\text { Number of } \\ \text { colonies } \\ \text { tested }\end{array} & \begin{array}{c}\text { Number of } \\ \text { pro } \\ \text { colonies }\end{array} & \begin{array}{c}\% \\ \text { pro }\end{array} \\ 251 & 42 & 17 \\ 225 & 168 & 75\end{array}$

The mutant isolation procedure applied to the pro- $6 \mathrm{su-19}$ strain provided several mutants unable to grow on the prolineless medium. They could represent: (I) back mutations in the su-I9 locus, (2) mutations in the major pathway of proline synthesis resulting in metabolic blocks between GSA and proline, (3) mutations in the alternative pathway of proline synthesis. Mutants of the first class can be easily distinguished as their growth responses are the same as of the pro-6 strain which grows on proline or arginine. Only one mutant which does not respond to arginine, but still grows on 
proline, was found; it will be henceforth referred to as ota-I. In order to distinguish whether this mutant belongs to the second or to the third class, it was crossed to the wild strain. The pro-6 and su-Ig loci are closely linked, thus if the ota-I mutation is concerned only with the supplementary proline pathway, $25 \%$ of proline requiring colonies should result from this cross rather than the $50 \%$ which would be expected if ota-I blocks the major proline pathway. The result (Table 2) is close to the former figure. To test the third possibility, i.e. that the ota-I mutation causes a metabolic block in the alternative pathway of proline synthesis, arginase and OTA activities were assayed. Strains carrying the ota-I mutation show no OTA activity, while arginase activity remains unaffected (Table I). The pro-6 su-I9 ota-I strain was tested in a heterokaryon against the pro- $6 \mathrm{su-I9}$ ota ${ }^{+}$strain; ota-I appeared to be recessive to the ota-I allele.

\section{Effects of the ota-I mutation in the pro-6 su-6 strain}

Mutations in the su-6 locus result in partial deficiency of ornithine transcarbamylase, the enzyme which converts ornithine to citrulline (Weglenski, I967). It was suggested that in suppressors strains of this type ornithine accumulates and becomes available for transamination to GSA. If this hypothesis is correct, the ota-I mutation introduced into the pro-6 su-6 strain should cancel the effects of the suppressor on the proline mutation. The pro-6, su-6 and ota-I loci are not linked; thus when ota- $I$ cancels the su-6 effect, one can expect $75 \%$ of proline requiring colonies among progeny of the cross between pro-6 su-6 and pro-6 ota-I strains. The results of this cross (Table 2) are in full agreement with this supposition.

\section{DISCUSSION}

The results presented in this paper show that the synthesis of arginase and OTA is controlled by the same regulatory system. Similar observations were made with Bacillus subtilis by De Hauwer, Lavalle \& Wiame (1964). These authors demonstrated the co-ordinate induction of arginase and OTA together with arginine permease and isolated mutants constitutive for all three enzymes. In terms of Jacob \& Monod (I96I) operon model, su- $I 9$ should be considered as a regulatory gene, while ota- $I$ as the structural gene for OTA. However, the presence of five suppressor mutations mapping in different loci but resulting in the same effects as the mutation in the su-I9 locus suggests that the genetic regulation of arginine break-down enzymes is complicated and can not be explained by the previously proposed models.

From properties of the ota-I mutant it can be concluded that the arginine-ornithine-GSA pathway is the only one by which arginine (and ornithine) can be utilised for proline synthesis. The results clearly show that the proline suppressors observed in this study cause the opening of this particular pathway. However, the proline suppressor mutants not linked to the pro-6 locus were found, which are active in the strain pro-6 ota-I being blocked both in major and alternative pathway of proline synthesis. The presence of suppressors of this type suggests a possibility for existence of a third pathway of proline synthesis in Aspergillus nidulans. Genetical and enzymological analysis of these mutants is now in progress. 


\section{REFERENCES}

Conway, E. J. (1962). Microdiffusion Analysis and Volumetric Error. London: Grosby Lockwood.

De Hauwer, G., Lavalle, R. \& Wiame, J. M. (1964). Étude de la pyrroline déshydrogénase et de la regulation du catabolisme de l'arginine chez Bacillus subtilis. Biochim. biophys. Acta 81, 257.

FORBES, E. C. (1956). Recombination in the pro region in Aspergillus nidulans. Microb. Genet. Bull. 13, 9.

JACOB, F. \& MONOD, J. (I96I). Genetic regulatory mechanisms in the synthesis of proteins. J. molec. Biol. 3, 318.

Lowry, O. H., Rosebrough, N. J., Farr, A. L. \& Randall, R. J. (195I). Protein measurement with the Folin reagent. J. Biol. Chem. 193, 265.

Pontecorvo, G., Roper, J. A., Hemmons, L. M., Macdonald, R. D. \& Bufton, A. W. J. (I953) The genetics of Aspergillus nidulans. Advanc. Genet. 5, $14 \mathrm{I}$.

WeGlensKI, P. (1966). Genetical analysis of proline mutants and their suppressors in Aspergillus nidulans, Genet. Res. 8, $31 \mathrm{I}$.

WeGLeNSKI, P. (1967). The mechanism of action of proline suppressors in Aspergillus nidulans. J. gen. Microbiol. 47, 77. 